\title{
9. Digitalisation: Distributive Force or Destructive Force?
}

By this point we have devoted a great deal of space to analytically dissecting digital capitalism. In the process, we asked the question, among others, of whether this term is helpful and judicious for understanding our current stage of economic, technological and social development. And yet, that was not the initial spur for writing this book or for theorising the concept of the distributive forces. Rather, the impulse came from my empirical research into and engagement with the ongoing changes we can observe in the processes and phenomena which are referred to as digitalisation, both in everyday language (with its corresponding inaccuracies) and in scholarly research. I have pursued this area of research ever since the 1990s, focusing especially on the interplay of technology and human labour. Initially, it was the technical aspects that drew my interest. At the time, however, the commercialisation of the Internet was still in its infancy, i.e. the Internet was hardly operational, let alone an established element in the workplace. And yet, it was already possible to identify new activities surrounding and linked to the Internet. Indeed, searching information on and via the Internet-so-called 'information broking'-constituted my first object of study (see Pfeiffer 1999b, 1999a), referred to in sociology as the 'micro-level' and the 'subject-level', i.e. an empirical approach. There, the focus was on specific forms of work and work tasks, and the method consisted of empirically reconstructing the development of the Internet and a qualitative analysis of Internet-based work. My aim was to illustrate the changes in the world of work resulting from the fact that both the tools and the products of labour were becoming virtual and non-material.

In a subsequent analytical step (see Pfeiffer 2014, 2004), I linked the level of specific workplace-based labour with a more general social perspective. Again, the aim was to empirically understand concrete forms of labour, which-proceeding from the example of e-services in mechanical engineering-are and will remain material but are increasingly complemented by a virtual dimension. In this process, digitalisation takes effect through its widespread operational application. And, indeed, the specific purpose for which it is deployed and the areas in which its introduction induces changes make a difference: tools/means of labour, labour capacity (the use value side of labour), labour power (the exchange value 
side of labour) or labour organisation - these are the very dimensions that Marxian analysis refers to as well. In the wake of the discussion at the time surrounding the so-called New Economy, I connected this perspective, which spans the micro and meso levels, with a critical discussion of the dominant existing hypotheses concerning the role of the Internet in ongoing changes in society.

Countless research projects and publications down the road, the hypothesis of the distributive forces materialised-at first, more intuitively, i.e. from observations of mine with regard to the most varied industries and business enterprises, which had accumulated over several decades. The corresponding, largely quantitative, empirical research first suggested and then increasingly confirmed-independently of the specific research question-certain dynamics that could neither be accounted for with the classic theoretical canon of the sociology of work and the sociology of technology nor be reduced to business strategies directed at - to put it in Marxian terms - the increase of relative and absolute surplus value. Although the empirical material and the statements made by business actors often reflected this in terms of impact (including on their own actions and decisions) they largely remained vague and imprecise with regard to the causes, frequently ascribed to globalisation, or the market. Of course, this is always true in a way, but by itself it fails to clarify the phenomena, dynamics and contradictions as a whole.

Over the years and decades of conducting empirical research, it also became increasingly obvious that workplaces themselves were changing. Organisational structures more and more reflected the external dynamics of globalisation and the market in all their varieties (relocation, outsourcing, mergers \& acquisitions, the permanent re-configuration of value chains etc.). Many of these dynamics became the research focus of the sociology of work. That said, the focus here was invariably on individual phenomena, mostly failing to take into account the specific function of technology and largely concentrating on the-doubtless, highly relevant-impact on workplaces (for the most part concerning the countries in which most global corporations' headquarters are located). These works found substantial evidence that the 'outside' was (and still is) increasingly becoming the principal action orientation on the 'inside'. No matter if technological-material restrictions, the actual access to or availability of resources, objectively required time intervals, or the professional assessments of expert technical staff in R\&D or production: all this was becoming less relevant, increasingly left unconsidered in project planning and calculations, and subordinated to the objectives related to value realisation (irrespective of how unrealistic these latter may have been).

At the same time, the logics of the non-value-creating, so-called indirect areas were becoming increasingly dominant both culturally and objectively. These areas were growing in numbers and branching out-along organisational units, work methods and distinct tasks. And even though their contribution to value generation in the stricter business-economic sense was less and less obvious, it became 
equally clear that their actual work object, alongside the permanent optimisation of the productive forces, was value realisation. The form of digitalisation that shaped workplaces, management decisions, labour organisation and work tasks more than anything else over those decades has received very little attention in the Internet-related diagnoses of contemporary society, including in those emerging from (sociological) research regarding the world of work: this refers to the IT systems that allow for the comprehensive interlinkage, control and prediction of all value-creating and value-realising processes (the best-known of which is SAP). All these observations and findings gradually combined into the distributive-force hypothesis elaborated in these pages, initially published in German (see Pfeiffer 2021, 2019a).

The essence of this hypothesis is quite simple: those productive forces which are geared towards surplus value realisation have become more dominant. The actual consequences for business enterprises and the corresponding actors, however, are anything but simple. And there are considerable analytical implications, too. This necessitates, first and foremost, the definition of an analytically independent term: the distributive forces. They comprise all technological and organisational measures and activities linked to surplus value realisation that aim specifically at value realisation (which is to be as risk-free, guaranteed and continuously expansive as possible). However, the distributive forces remain part and parcel of the development of the productive forces; they are neither separate from them nor are they replacing them. And yet, the distributive forces-as part of the productive forces-are becoming more significant in relative terms. This has systemic reasons behind it (which are to be found in the logic of advanced capitalism) and it explains the countless phenomena of digitalisation and their success, much more clearly and profoundly than can be done without this particular analytical lens.

In this sense, the original intention motivating this book was not an analysis of digital capitalism or an engagement with this term. My aim was, rather, to attain a deeper understanding of the changing empirical phenomena in workplaces, in the design of labour processes and in the deployment of technology-although the latter was, of course, increasingly being shaped by (and, discursively often reduced to) digital technologies. Equipped with the theoretical concept of the distributive forces, then, the question of what is or may be new about digital capitalism can be addressed in a new and different way. For it is perhaps no coincidence that the digital technologies, their forms of use and the associated business models of digital capitalism display their particular strength largely in the field of the distributive forces. One of the central aims of this book is to expose precisely this.

The Digital may constitute the new element in current capitalism. However, the Digital has become so significant essentially because it revolutionises the distributive forces geared towards value realisation. And that is precisely what advanced capitalism urgently requires. Digital business models rely above all 
on the promise of infinite market expansion, ubiquitous consumption and thus almost guaranteed value realisation. Needless to say, nothing could be more enticing for an (inevitably over-)producing company than such a promise.

With regard to value generation, digital capitalism has little novel about it (even though one may get this impression at a phenomenal and most certainly at the discursive level). The increasing importance and general enhancement of the distributive forces are a reflection of present-day (digital) capitalism's efforts to mitigate the causes of crisis that haunt advanced (industrial) capitalism. That is its-essentially irredeemable-promise. Yet, because the manufacturing enterprises of industrial capitalism have long reached the limits of optimising and expanding their productive forces towards maximum achievable value generation, and successful value realisation thus constitutes the main problem they face, they tend to believe the somewhat implausible promises attached to the digital distributive forces.

Incidentally, for those who continue to harbour reservations vis-à-vis Marx's wording, all this can also be expressed entirely without using Marxian terminology. In management and consulting jargon, it would sound a bit like this: in the competition for innovation and production, business enterprises in the manufacturing industries have been optimising their production processes for decades, building global value chains and producing more and more goods, and doing so ever-more cheaply. On a global scale, competition is growing increasingly intense as a result. Innovation and production processes and the potentials of global value chains, however, have largely been optimised to their very limits, and even digital technologies have little to offer in the way of further productivity gains. The increasingly crucial competitive factor is thus the successful development of new markets and the more rapid conclusion of sales than the competition. That is the reason why more and more efforts and funds are dedicated to advertising and marketing (the stimulation of consumption), warehousing and transport (quicker access to the points of sale) and the prediction and control of sales (connecting the market to production more accurately and in real-time). Here, digital technologies (particularly AI and Big Data) and digital business models (based primarily on personalised advertising and the spatial and temporal multiplication of the point of sale) promise an effective solution. Seeing as markets and consumption are limited, it is those enterprises who implement digital transformation without hesitation and particularly comprehensively that will benefit the most from these opportunities. ${ }^{1}$

1 Incidentally, the same also applies - albeit with a slightly different wording, and after replacing certain terms - to national economies (and the competition among them) and their political representatives. After all, while national perspectives and corresponding patterns of reasoning are generally met with a modicum of scepticism, not least for historical reasons, particularly in Ger- 
The starting point of the hypothesis developed throughout this book, of the distributive force as the actual dynamic of digital capitalism, was just that: digital capitalism. Chapter 2 began with an extensive and critical engagement with the authors who place the term 'digital capitalism' at the heart of their analysis: Dan Schiller (2014, 1999) and Michael Betancourt (2015). The thematically structured engagement with these two authors revealed a first blind spot, which they partly do explicitly expose, and partly address only in very vague terms, but which neither of them clarifies in a satisfactory way. Namely, where and through what mechanisms is value being generated? Have there been any fundamental changes in this regard under digital capitalism?

Chapter 3 pursued these questions, based in part on Karl Marx, but primarily on Mariana Mazzucato (2018), who demonstrates how the question of value generation has been systematically marginalised by economic theory. What became clear was that nothing has fundamentally changed with regard to the source of value generation: human labour; this dimension does not indicate anything that could be identified as systemically new, i.e. a qualitative economic difference between old and new, that is, between industrial and digital capitalism.

Continuing our search for what is really new and transformative in digital capitalism, in Chapter 4 we returned to the classic analyses of the emergence of industrial capitalism developed by Karl Polanyi and Karl Marx. While Polanyi's focus is on the buying side (particularly concerning labour power), Marx concentrates on the production process and the use of human labour power to create value (and its unilateral appropriation by the capitalist). The other end, if you will-the selling side-features only marginally in both, albeit not as the actual object of study, but merely as a structuring condition for their analyses.

This revealed the second blind spot in the understanding of the new element(s) of digital capitalism, namely value realisation, which is becoming increasingly significant in advanced capitalism (whether digital or otherwise). Chapter 5 more fundamentally elaborated this hypothesis, proceeding theoretically from Marx and, basing itself on empirical examples, in terms of three dynamics: market expansion, consumption and crisis. Business enterprises are increasingly forced to deal with these dynamics in order to guarantee, as comprehensively as possible, repeated value realisation over and over. Chapter 6 described the corresponding productive forces aimed at this dimension in terms of three central distributive forces: advertising and marketing, transport and warehousing, and control and prediction. These three distributive forces were then analytically and historically elab-

many, politicians and ministries at the EU, national and regional levels certainly do argue from a national perspective when it comes to the competition between national economies over pole position in digital capitalism, proclaiming economic success as the goal of the entire nation and thus of all its citizens. 
orated and, drawing on empirical examples, illustrated and spelled out for the present.

In concluding our theoretical reflections, remaining unanswered questions on the distributive-force hypothesis were resolved by adding a few necessary specifications, distinctions and clarifications-especially regarding the concepts of circulation and of the development of the productive forces. This rounded out the theoretical framework expounded in the two preceding chapters. Chapters 5 to 7 thus represent both the theoretical centrepiece of this book and the analytical foundation of the distributive-force hypothesis. Chapter 8 then empirically illustrated these theoretical deliberations with a view to central actors of digital capitalism, catalysts for value realisation, considerations on merchant capital 4.0 and, finally, activities related to the distributive forces.

We had already identified two blind spots in the diagnoses that address digital capitalism: in Chapter 3, we discussed the disappearance of the source of value genesis from economics, and, in Chapter 5, we depicted the underestimated dynamism of, and relentless thirst for, value realisation. Yet the drama of capitalism comprises several acts: in the first act, value is generated, in the second act only some of that value is realised, and, in the third act this realised value is then unilaterally appropriated. In this play, which we have been performing for quite some time now - the only show in town, with no alternatives scheduledthe main plot has long ceased to circulate around question of distributing more value more fairly. The actual drama is the play itself: for the logic of value generation and of value realisation inherent in our mode of production leads to a perpetual devaluation of everything, as underscored by the reconstruction presented by Raj Patel and Jason Moore (2017). This devaluation of nature, money, labour, care, food, energy and life is not a side-effect, but a strategy: "[...] cheapening is a set of strategies to control a wider web of life." (ibid.: 3) The authors drastically illustrate this (or, rather, illustrate how drastic this is) based on the example of chicken. The short passages and cursory figures presented in the introduction (see ibid.: 3-6) alone indicate that the play, which Marx would entitle 'the destructive forces', and Polanyi the 'annihilation of substance', has been performed for far too long and too often-the stage, the set, the props, the actors and the audience are all equally at the end of their rope. Still, no one is closing down the theatre, nor will there be a new season with a new playbill: "[I]t's easier for most people to imagine the end of the planet than to imagine the end of capitalism." (Patel/Moore 2017:2)

My intention is not to conclude this book by simply presenting a condensed summary of what has already been elaborated theoretically and empirically across so many chapters and pages. Proceeding from Marx, and going beyond his analysis, the productive forces have here been complemented with the distributive forces. Rather, basing ourselves on these deliberations, we ought to shift our attention to two additional dimensions that warrant consideration: reproduction 
and destruction. Conceiving of both as one, we are inevitably confronted with questions of ecological sustainability and to what extent our economic system is contributing to the multiple ecological disasters that can already be felt all around us. So, finally, in our search for a solution to the dilemma, we will briefly direct our attention to a specific manifestation of digitalisation: Artificial Intelligence and Machine Learning (henceforth referred to as AI/ML). Yet, before we do so, our argument requires a small analytical bridge-namely from the productive forces and the relations of production to the relations of reproduction and the destructive forces:

- Except for the basic inescapable material (i.e. physical, biological or ecological) needs of human beings, society and nature, all other needs (or, rather, their satisfaction) depend, both materially and socially, on the given productive forces and are tied to the existing relations of production. In industrial capitalism, the deployment and the development of the productive forces are driven by the goal of maximum surplus value generation.

- The material and (ultimately) ineluctable basic needs of humans, society and nature-the reproductive forces-are equally determined by the relations of production. Given that capitalism is always about maximising value, reproduction inevitably increasingly fails to attain the scope that would be both possible and necessary. As a result, the relations of reproduction themselves increasingly become a social question. This is one reason, among others, why it merits a term in its own right.

- Over the course of capitalism's development, the distributive forces, as a part of the productive forces, become increasingly significant. Their deployment and development are propelled by the hunt for a maximisation of opportunities for surplus value realisation. The distributive forces and the productive forces mutually reinforce one another. Distributive capital, for its part, relies principally on the promise (both to productive capital and its own investors) of value realisation and market expansion. Thus, the potential, harboured within technological progress, to protect and preserve actual substance is mostly left idle.

- Current digitalisation is being harnessed mainly for the purpose of value realisation, thereby advancing, above all, the development of the distributive forces. This engenders new configurations in the relations of distribution: new (global) inequalities between capital and labour, and between business enterprises located at the opposite ends of the development of the productive or distributive forces.

- Over the course of current digitalisation, the distributive forces and the productive forces are mutually reinforcing one another at an ever-faster pace. This further exacerbates the contradictions between distributive capital and 
productive capital, while the relations of reproduction are increasingly becoming the all-determining existential question for everything and everyone.

In a few instances in Karl Marx's works, we can find both the term 'forces of destruction' [Destruktionskräfte] and 'destructive forces' [Destruktivkräfte]though he refers to the exact same thing. Yet, in neither case does he refer to productive forces-i.e., conceived in a more technological sense-that might have a destructive effect (such as, say, weapons). To him and Friedrich Engels, it is the general consequences of capitalism's relations of production as such that are destructive: "In the development of productive forces there comes a stage when productive forces and means of intercourse are brought into being which, under the existing relations, only cause mischief, and are no longer productive but destructive forces (machinery and money)", as a result of which "a class is called forth which has to bear all the burdens of society without enjoying its advantages" (Marx/Engels 1976b: 52), and which will therefore initiate the revolutionary transformation of society, as Marx and Engels famously hoped. So, the main issue here is the destruction of the social, caused by the growing, economically induced rift between two classes in society.

Yet Marx also takes into account the destructive capacity directed against nature (i.e. both the natural world and human nature): in his view, capitalism implies not only a novel and unprecedentedly successful mode of production (which may have emerged repeatedly throughout history, but never in such a comprehensive form), but "a system of universal exploitation of natural and human qualities, a system of universal utility, [...] and under these conditions nothing appears as something higher-in-itself, as an end in itself, outside this circle of social production and exchange" (Marx 1986: 336-337). That is to say, everything is subordinated to economic objectives and henceforth considered exclusively from this perspective. In this sense, both the environment and the social equally become the object of exploitation. Capital organises a "universal appropriation of nature and of the social nexus itself" (ibid.). Nature finally turns into "purely an object for men, nothing more than a matter of utility. It ceases to be acknowledged as a power for itself, and even the theoretical cognition of its autonomous laws appears merely as a stratagem for its subjection to human needs, whether as object of consumption or as means of production" (ibid.: 337 ). One aspect that emerges more clearly when we read the entire passage, rather than just this short extract, is that Marx's comments in this context also concern science, which provides its knowledge of the natural laws to the economy, thus essentially becoming complicit by facilitating the abandonment of long-standing practices that are more in tune with nature's needs: this would refer to, say, "nature worship, as well as [...] the traditional satisfaction of existing needs and the reproduction of old ways of life confined within long-established and complacently accepted limits" (ibid.) In this sense, "[c]apital 
is destructive towards, and constantly revolutionises, all this, tearing down all barriers which impede the development of the productive forces, the extension of the range of needs, the differentiation of production, and the exploitation and exchange of all natural and spiritual powers" (ibid.).

It would be a misinterpretation of Marx to read these lines in the sense of techno-pessimism or even as a plea for a return to pre-capitalist times. Firstly, he is fully aware of historical precursors that already displayed features of the exploitation of human beings and nature. Secondly, he simultaneously acknowledges the positive effects of the unleashing of the productive forces, the scope of which had been inconceivable prior to the arrival of capitalism. Yet that does not stop him from also pointing out the destructive elements-particularly the ones which are systematically and inevitably destructive. Hence, Marx's diagnosis that (if you will) the use of humans, nature and society leads to their depletion entirely concurs with Polanyi's (see Chapter 4.1). At any rate, Karl Marx would not, per se, attribute technology a destructive potential, but certainly would do so when considering it as a productive force within the capitalist mode of production, which in his view is inevitably destructive.

We have seen that all the digitalisation strategies characteristic of distributive-force capitalism (see Chapter 6) aim primarily at growth. This was first theoretically substantiated (Chapter 5), then developed analytically (see Chapter 7) and, finally, illustrated empirically (see Chapter 8). In conclusion, the connection between digitalisation and growth appears immanently close, inextricably interwoven, at least under the conditions of this economic system. And, above all, it is ecologically disastrous. Just how disastrous these consequences will be in the absence of major changes has more recently been calculated on the basis of disconcertingly modest figures: according to this calculation, a catastrophic collapse of human society is currently the most likely scenario given the high levels of resource consumption (the study focuses specifically on the correlation between forest areas and population). Even in the most optimistic model calculation, the likelihood of our civilisation surviving is less than 10 per cent (see Bologna/Aquino 2020). For those of you who are still fairly relaxed and expect this scenario to materialise in a few centuries or so-if at all-I am afraid you can enjoy this moment only for another second or two: the authors also emphasise that the time horizon for the onset of this catastrophe is between two and four decades (see ibid.: 5). This places the ultimate disaster in such close proximity to our present that it will occur the lifetime of many of us, and most certainly during that of the next generation. Admittedly, the study can by all means be critically challenged, just like any other one based on model calculations. Moreover, most of us would surely hope that someone has committed a serious calculation error here, prompting entirely misleading forecasts. But such dramatic prospects have long become commonplace, no matter how you choose to look at it: the overexploitation of existing nat- 
ural resources is obvious, and the end of what is finite is, in logical terms, only a matter of time. That is, if we continue as today-but not if we finally put an end to the annihilation of finite resources.

Today's shocking figures beg an old and familiar question: can ecological sustainability and economic growth be reconciled, or, better yet, be combined to produce a kind of win-win situation? After all, the idea of the (New) Green Deal suggests just that-from the original conception of the term (see Friedman 2007) to the current targets stipulated by the European Union (see EU 2019). However, as pleasing to our ears as this may be, it is equally unrealistic. Jason Hickel has provided empirical evidence for this with reference to the United Nations' Sustainable Development Goals (SDGs), which also inform the corresponding EU targets. According to Hickel, the contradiction between growth and ecology, essentially codified in these targets, is irresolvable: while, on the one hand, five of the 17 goals call for a harmonious relationship with nature and the protection of the planet against environmental degradation, at the same time the SDGs set a firm goal of three per cent annual growth. ${ }^{2}$ The incompatibility is to be compensated through efficiency increases. Hickel refutes such notions, drawing on empirical data on resource consumption and carbon emissions to conclude that the targeted growth and sustainability goals are fundamentally irreconcilable:

"In light of the empirical evidence [...] we can conclude that there are strong indications that Goal 8 (to sustain aggregate GDP growth at $3 \%$ per year) is incompatible with the sustainability objectives on resource use and climate change." (Hickel 2019: 878-879)

This hope of decoupling-i.e. the reduction of resource use while maintaining a growth path-has more recently been debunked by others as an outright "myth of decoupling" (see Jackson 2017: 84-101). Growth and ecological sustainability thus remain locked in irreconcilable opposition. And this is valid not just because Polanyi and Marx theoretically asserted this, but also in very concrete, up-to-date and empirical terms. Economics, at least in its present state, appears to have no answer on offer. ${ }^{3}$ Technology, by contrast, is something that people place great

2 This growth target of three per cent is perhaps no coincidence given that it is considered to be the minimum figure needed for the continued functioning of the capitalist economic system: "[Capitalism] depends on the capacity to achieve 3 per cent compound growth." (Harvey 2011a: 130)

3 Concepts of an ecologically oriented economy explicitly opposed to growth date back to the 1970s; a dedicated international scholarly conference was first held in 2008 (see Flipo/Schneider 2008), firmly establishing itself since then through its regular occurrence. Just recently, a comprehensive volume was published that assembles scientifically-based action recommendations for political decision-makers as well as concepts for transitioning to a degrowth society (see Stuart et al. 2020). 
hopes in, particularly concerning the issue of resource efficiency or resource avoidance. In this vein, the German Federal Ministry of the Environment, Nature Conservation and Nuclear Safety (BMU) likewise attaches considerable expectations to the conceptual combination of ecological sustainability and technological innovation. The ministry envisages the two forming a "Dream Team" (see Schulze 2019) - even though the responsible federal minister is fully aware that digitalisation could act as "fire accelerant" of ecological and social crises as well (see ibid.; translation amended).

Throughout this book, we have repeatedly mentioned the ecological consequences of digitalisation and the distributive forces: for example, in the context of crypto mining, during our engagement with Michael Betancourt (see Chapter 2.4), while discussing the material aspects of digitalisation and the use of rare earths in the manufacturing of AI-related hardware (see Chapter 2.3) or with regard to the ecological impact of large cargo ships (see Chapter 6.2). In our concluding summary, we must distinguish between the following three sources of ecological impact that need to be analytically separated. They include, firstly, the capitalist mode of production, which so crucially depends on market expansion and growth; secondly, specific phenomena linked to the development of the distributive forces; and, thirdly, digitalisation itself. All three levels are closely interconnected and, in truth, would each warrant a separate analysis as well as a detailed exploration of their mutual interplay. However, I have no intention of elaborating such a detailed account here. Yet in order to highlight the consequences directly linked to digitalisation as such, we cannot evade the question discussed in the following final sections of this study. While the current discourse concentrates primarily on the already barely containable environmental degradation caused by physical-material industry or transport-related carbon emissions, it often goes overlooked that digitalisation itself-as virtual as it may appear-entails very real material and physical ecological damage (not to mention the intentional and inherent social consequences of a distributive force capitalism). Just to get an idea of the extent of ecological damage caused by digitalisation, here are but a few examples:

- During the decade following the release of the very first iPhone in 2007, the share of the world's carbon footprint owing to information and communication technologies as a whole (software and hardware) tripled (from one to three per cent). It is estimated that this figure will reach 14 per cent by 2040 (see Belkhir/Elmeligli 2018).

- The production of ever-larger and more powerful screens for smartphones entails significantly higher carbon emissions than did previous mobile phone models (see Suckling/Lee 2015). And there certainly is no indication that new technologies will improve this situation: the carbon emissions of an iPhone 7 were 10 per cent higher than those of the iPhone $6 \mathrm{~s}$, the production of which in 
turn had already increased carbon emissions by 54 per cent compared to the iPhone 4. Besides this, the recycling rate of smartphones is extremely low (see ibid.).

- A single Bitcoin transaction requires as much electricity as an average household in the Netherlands uses per month (see Vries 2018). Some projections predict-based, however, on user numbers, not on transactions-that the use of Bitcoin alone would cause sufficient carbon emissions to drive global warming above the 2-degree mark within three decades (see Mora et al. 2018). This merits special emphasis: even if all other $\mathrm{CO}_{2}$ emissions were brought to zero, Bitcoin transactions alone would cause global temperatures to rise by 2 degrees-and Bitcoin is just one among thousands of cryptocurrencies.

- The sharing economy is also part of the problem: for example, e-scooters in a sharing model without a fixed station produce more than half the amount of carbon emissions caused by a private car (with a combustion engine), while an e-bike's carbon footprint per mile is five times that of a conventional bicycle (see Hollingsworth et al. 2019). Added to this is the fact that these models are not even worthwhile economically: car sharing in Germany is profitable only in the few inner-city districts of large cities with a high population density; and yet, only five per cent of the population live in such areas.

It could be objected-and you may well feel this impulse yourself while reading these lines-that these are examples of the old digitalisation, but that the emergence of $\mathrm{AI}$ and ML today heralds a new generation of digital technologies that offer unprecedented opportunities for tackling ecological challenges. Some may also notice at this point-should they have read through all preceding chaptersthat the topic of AI/ML has not featured prominently or explicitly in this book thus far.

Of course, it is hardly possible to write about digital capitalism during the 2020 s without addressing Artificial Intelligence and (self-)learning systems (i.e. Machine Learning or Deep Learning). Many of the empirical phenomena associated with the distributive forces in digital capitalism are already using AI/MLwhich applies in particular to advertising and marketing (see Chapter 6.1), but also increasingly to transport and warehousing (see Chapter 6.2) and, above all, to control and prediction (see Chapter 6.3), the latter of which links up advertising and marketing with transport and warehousing and increasingly connects them to specific production locations along global value chains and the many places of and opportunities for ubiquitous consumption (see Chapter 8.2). None of this is conceivable any longer without AI/ML, but neither can it be explained or defined 
(neither technologically nor analytically) by this relatively recent facet of digitalisation alone. ${ }^{4}$

Currently, the more recent business models pursued by the major digital corporations and in the start-up and platform economy (see Chapter 8.1) are largely based on the use of $\mathrm{AI} / \mathrm{ML}$ and often attract the interest of investors precisely for this reason (see Chapter 8.2). Similarly, today's hardware-from the gadgets that enable ubiquitous consumption to the technologies of Industry 4.0-is inconceivable without $\mathrm{AI} / \mathrm{ML}$ elements (see Chapter 8.3). In this sense, there is nothing special about $\mathrm{AI} / \mathrm{ML}$, it is merely a more recent technological facet of digitalisation. In other words, AI/ML generally changes nothing about the preconditions or validity of the political-economic analysis of digital capitalism presented here. Therefore, so far, there was no need for a chapter on AI/ML specifically, and this book's line(s) of argument shall not be unravelled again in this final recap.

Yet from the perspective on reproduction and distribution which we are contributing here, this sideways glance is certainly worthwhile. For we do require clarification on the question of whether digitalisation has continued to develop in such a way that previously existing dilemmas of productive-force and distributive-force capitalism could be resolved through technological means. Might it be possible that precisely these smart, self-learning and autonomous algorithms can help us reconcile growth and ecology, seeing as we are unable to do so ourselves given our limited human intelligence? There are numerous science-fiction narratives in this vein, but also those diagnoses which offer the optimistic assessment that intelligent technology will compensate for humanity's ecological stupidity (i.e. destroying its natural basis of existence through its own actions).

As concerns $\mathrm{AI} / \mathrm{ML}$, we must address two exemplary questions-which would in fact apply to all the other phenomena of digitalisation as well. The answers may help us gauge whether the development of the productive forces and the distributive forces in capitalism would also allow for fundamentally different forms of use-which would not be (or at least not primarily) driven by the need to constantly reach the next stage of maximum value generation and value realisation.

4 Of course, there are fierce disputes over how 'recent' Artificial Intelligence actually is. One historical account, for example, regards Al as an expression of humanity's general propensity for numbers-based knowledge and thus dates its beginnings to the 6th century AD (see the time series according to McCorduck 2004: xxiii and 523). Alan Turing is credited with having been the first to raise the question, during a symposium in 1947, of whether machines are capable of thinking. Yet the actual - in a sense institutional - founding of $A l$ is commonly attributed to a conference that took place at Dartmouth College in Hanover, New Hampshire, in 1956 (see Konrad 1998; Nilsson 2010: 52-56). Only since the late 1980s, however, have there been repeated leaps in the computing speed of processors that allow for the realisation of more recent Al approaches such as Unsupervised or Reinforcement ML (see ibid.: 413-421), or Bayesian networks (see ibid.: 381-397), which Al today usually denotes. 
This pertains, firstly, to the question of whether the paramount (and, logically irresolvable) contradiction between endless growth and the finiteness of natural resources (which Karl Polanyi regards as the crucially threatened substance in capitalism, alongside the human substance of society; see Chapter 4.1) can be resolved or mitigated, if not economically or politically, then at least technologically. So, could AI/ML contribute to the conservation and protection-and, above all, a more moderate use-of nature and natural resources? Or, in other words: does AI/ML harbour a utopian potential, in which this digital technology could be deployed, so to speak, as a reproductive force? After all, many people associate AI/ ML with the prospect of being able to reconcile ecology and capitalism-and thus (not for the first time in the history of digitalisation) with the hope of transcending immanent economic restrictions. The second question we seek to answer here is whether AI/ML could-as the vast body of dystopias dealt with in popular culture and debated throughout society would suggest—instead become a particular destructive force distinct from all other digital technologies.

Let us begin with the positive aspects. The BMU apparently has great faith in the ecological opportunities provided by $\mathrm{AI} / \mathrm{ML}$, funding some 50 corresponding projects in in the context of a $€ 27$ million strong programme set up in 2019 (BMU 2019). The objectives deemed worthy of grants include: the preservation of biodiversity; the promotion of nature-compatible agriculture, sustainable consumption or sustainable mobility; transparency and utilisation of environmental data and thus a more reliable basis for decision-making concerning environmental-protection policies; a reduction of the demand for energy and resources; and ensuring protection standards and ecologically oriented programming of AI algorithms (see ibid.). So, can digitalisation, and $\mathrm{AI} / \mathrm{ML}$ in particular, (also) open up a development path towards post-growth? And, if so, in what way(s)? Some promising applications are already underway (including among the projects funded by the BMU), though they are, of course, far more quickly conceptualised than implemented. The following examples, however, underscore that the technological options for reproduction can always be easily complemented with a 'but', pointing to economic restrictions and thus destruction:

- For example, personalised medicine could save lives and prevent resistances that also affect eco-systems. However, this is not possible given a pharmaceutical industry that already tolerates supply shortages for certain (mass)medicines today (simply because the profit margins are too small) and conducts $\mathrm{R} \& \mathrm{D}$ in a way that medical therapy implies not the healing of patients but rather their lifelong dependence on medication.

- Drones, for instance, could detect the nests of ground-breeding birds in fields and allow for their removal before harvesting machines destroy them. However, this is not possible given an industrial agriculture which-due to the quest 
for endless productivity increases and the disastrous combination of genetically modified seeds and aggressive chemical fertilisers-has effectively already almost wiped out these ground-nesters through the destruction of their food chains.

- Personalised on-demand production could lead to all kinds of product-related resource consumption being reduced and occurring only when specific individuals have indicated their specific demand via an online order. In ecological terms, this would represent a huge lever for curbing today's volumes of mass-produced goods. However, this is not possible if, even in those areas where this would have been technological feasible for years, such as in the car industry, the all-determining indicator of Overall Equipment Effectiveness (OEE) commands the continuation of production in a 24-hour shift system even in the absence of demand.

- For example, the targeted carbon-neutral production of many car manufacturers combined with the shift to e-mobility-currently frequently linked to the target year 2030-could indeed make a huge difference. However, this is not possible if these widely marketed plans are tied to implausibly high growth and profit targets (adding to the other unresolved ecological questions concerning e-mobility)..$^{5}$

- A perfect mix of road and rail, depending on the specific goods and transport routes, could serve to organise logistical flows of goods in an ecological manner. However, this is not possible if the Deutsche Bahn (German rail) continues, as it has done for decades, to decommission rail lines dedicated to freight because they are not sufficiently profitable (and: indeed, is forced to do so because the Deutsche Bahn's policies continue to stipulate profitability as the decisive criterion for continuing a given route's operation).

- Digitalisation could help detect polluters all around the world and even in remote areas, or track down, for example, the large-scale illegal extraction of natural resources. However, this is not possible as long as there are business models such as that of the Nestlé corporation-meaning: the radical exploitation of regional groundwater reservoirs in order to sell this water in (plastic) bottles-and these business models are legally and politically enabled and protected.

5 This applies to one example from my research that exhibits an annual productivity increase of five per cent and an ROS increase of 6 per cent per annum. Specifically, a particular manufacturing line in the surveyed company, which today produces 200,000 vehicles with an internal combustion engine each year, is supposed to produce 250,000 vehicles of the same model peryear as an electric car in the future. This implies an increase in carbon emissions of 25 per cent. 
The subjunctive 'could' in each of these examples is, of course, not related to the question of technological feasibility. All of it is already technologically feasible today, or could at least be realised in a very short period of time. And yet, digitalisation and $\mathrm{AI} / \mathrm{ML}$ will not be used for ecological purposes (at least not on a broad scale and beyond the funded projects) as long as ecology is faced with economic interests. In the absence of fundamental changes in the relations of production and distribution, we will be unable to deploy both the productive and the distributive forces as an enabler of a socially and ecologically sustainable mode of reproduction. Let us take this thought one step further and consider AI/ML technologies themselves (and not only the context of their economic embedding) with a view to their potentially destructive character. AI in particular is often attributed, both in literature and academic discourse, a special dystopian potential.

Let us start with the question of growth. Needless to say, AI/ML is not primarily being marketed as a technology that limits or even prevents growth, but, on the contrary, linked to promises of growth and market expansion. The consulting industry is even portraying $\mathrm{AI} / \mathrm{ML}$ as the indispensable precondition for "survival and success" (PwC 2017: 24) on the markets. According to consultants, AI/ML will lead to a global GDP increase of around 14 per cent, driving it to $\$ 15.7$ trillion by 2030 (see ibid.: 5); $\mathrm{AI} / \mathrm{ML}$ is expected to engender productivity increases of 55 per cent and growth rates of 58 per cent in the field of "consumption side impacts" (ibid.: 7)-meaning that the greater part of related activities is geared towards the distributive forces. Although a more recent study does present a markedly lower growth estimate of the global market for AI/ML (39.9 per cent for 2019), the forecast annual growth rates are much higher (42.2 per cent) (see GVR 2020). Of course, there are always interest-driven reasons for such studies to 'think big' and perhaps offer very optimistic calculations. So far, even the experts' predictions regarding the proliferation and use of AI have proven rather inaccurate (see Armstrong et al. 2014). Nor are exaggerated expectations a new phenomenon: in the past, too, during the first stage of AI from 1983 to 1993, average annual AI-induced revenue increases in the United States were-quite optimistically-predicted to range from 29.4 per cent (use in $R \& D$ ) to 118.1 per cent (use in private households) (see Klotz 1986: 562). The numbers aside, this clearly shows that, upon closer inspection, AI/ML technologies turn out-just like all other productive and distributive forces - to be destructive, at least in the analytical sense, simply because they are part and parcel of production processes. They thus become the crucial enablers of the current development of the distributive forces, leading to growth and an unequal distribution of capital and risks.

A second probe concerns AI/ML's ecological footprint. We have seen earlier that digitalisation as such-despite its alleged immateriality-produces a considerable and thoroughly material ecological footprint. Unfortunately, this is no different in the case of $\mathrm{AI} / \mathrm{ML}$, and indeed its actual extent is quite shocking: the carbon 
emissions caused by the training of just a single $\mathrm{AI} / \mathrm{ML}$ algorithm are almost five times that of an average car with an internal combustion engine (including that car's production and use over its entire lifespan), or the same as 300 return flights between San Francisco and New York City (see Strubell et al. 2019). The carbon emissions produced in order to develop AI to a level that could make it into an academic journal-i.e. not remotely close to any real forms of application yet-are equivalent to those accumulated over half a car's lifespan (see ibid.). And the number of such learning and training processes is rising (see Schwartz et al. 2019): the sum of computing operations per learning process is doubling every 3.4 months, increasing at an exponential rate; from 2012 to 2018 , these operations increased by the staggering factor of 300,000 (see Amodei et al. 2019). ${ }^{6}$ So, the available empirical figures illustrate that there is no reason to expect an effect of AI/ML on growth and carbon footprint that would enable an enhanced reproduction of nature. On the contrary: $\mathrm{AI} / \mathrm{ML}$ is exhibiting the familiar destructive tendencies propelled by both the digital and non-digital productive and distributive forces.

This leaves, finally, a level of investigation that takes the technology itself into view and explores whether it may harbour destructive potential even beyond its economic use. After all, according to some, nothing could be more certain, considering such delightfully shocking terms as "weapons of math destruction", coined by Cathy O'Neil (see 2016).

This refers to the intentionally destructive deployment of technology: AI/ML can be used (like almost any technology) for intentionally and directly destructive purposes. The effects of this use may be most obvious and immediate in the military context, but its impact in the manipulation of opinion can also have (and is already having) destructive consequences for democratic structures and participation (see, e.g., Hesse 2020). Such intentionally destructive use may, therefore, be anything but exclusive to $\mathrm{AI} / \mathrm{ML}$, but here the implications are far less containable and partly irreversible.

What I would regard to be much more intriguing and concerning-and much less debated, by contrast-is the unintentionally destructive deployment of $\mathrm{AI} / \mathrm{ML}$, which occurs as a result of uninformed application and unprofessional handling and is, in a way, a specificity of $\mathrm{AI} / \mathrm{ML}$ (in particular with regard to learning processes, algorithms, data, scales of measurement, etc.). Proceeding from my own empirical observations concerning strategies of $\mathrm{AI} / \mathrm{ML}$ deployment in workplace contexts, pursued by typical German business enterprises over the past two years,

6 The original study is from 2018, the version cited here was corrected in 2019-yet not with regard to the numbers it calculated, but because of its originally inaccurate representation of Moore's Law. The study compares the required Petaflops per day for some prominent examples, from Alex Net in 2012 to AlphaGoZero in 2018. 
the following forms of unintentionally destructive use deserve brief mention (and require a systematic research perspective for the future, too):

For example, such unintentionally destructive deployment of AI/ML can be witnessed when the simplicity of the statistical model is completely overestimated while the complexity of the selected context of application is underestimated. Because causalities are implied where there is only data static. Because algorithms, which tend towards the (statistical) centre over the course of their learning processes, discard objectively relevant observations as statistical outliers. Because the knowledge of data-adequate scales of measurement and the requirement of their compatibility with the selected algorithm is lacking. Because knowledge is lacking of the required compatibility of both (the scales of data measurement and the algorithm selected) with the objective conditions of the context of application. Because implementation is often left exclusively to information and data scientists without consulting the experts from the context of application concerned. Because data is used simply because it exists, without questioning its factual validity (focusing instead on its mathematical accuracy). Because data as such is already systematically distorted from the outset, reflecting real (desired or undesired) imbalances in society or in the context of application which, in the absence of corrective weighting, are then perpetually reinforced over the course of autonomous processing. Because data also displays a less obvious distortion which objectively arises from the particular ease or difficulty of its collection-the lack of awareness of which, however, prevents a corresponding corrective weighting. Because it remains entirely unclear in the case of many AI/ML applications how long the learning process is supposed to last, and based on what data, and whether this must occur only initially or be repeated on a regular basis-and what criteria should guide these decisions.

The destructive consequences of AI/ML may also materialise simply because $\mathrm{AI} / \mathrm{ML}$ processes are being used-in an aimless embrace of their hip-ness-even in contexts where fixed coding or a relational database would produce more adequate context-related results with less effort. And, finally, destructive use of AI/ ML may occur when it is regarded as a technology that cannot as such be shaped or influenced and hence none of the questions of design and decision-making essential for its constructive deployment are even considered. Besides this, AI/ML poses a new challenge which will confront us all, and which does not present itself in this form in other fields of technology and digitalisation: we need to answer the question of how we want to use results in our everyday work context that may appear as an unequivocal and objective fact but are really no more than a more or less accurate, calculated prediction (meaning, in the individual case, they can also always be false positive or false negative).

All this will perhaps remain without consequences, or simply become a nuisance, rather than destructive in the proper sense. And yet, at any rate, data will 
already have been generated and analysed, learning processes initiated-and a corresponding ecological footprint produced regardless. So, there is always a degree of destruction. It must be noted, however, that there is a clearly discernible difference between the potential unintentionally destructive impacts: if AI/ ML fails to function properly in the area of the distributive forces, usually nothing dramatic happens. In the worst case, certain target groups receive incongruous advertising messages or annoying purchase recommendations, certain sales predictions fail to materialise as expected or a package is delivered to the front door not quite as promptly as promised. Yet, wherever AI/ML-based decisions concern what Polanyi refers to as substance (individual health, social cohesion, nature's reproductive capacity) or the material base of essentially all productive forces (raw materials, production methods, infrastructure), erroneous decisions made by AI/ ML (or: the misinterpretation of generated results) can entail dramatic and often irreversible consequences. This could mean that the machine malfunctions; the infrastructure is overstretched; people die; the machine's polarising articulation causes irreconcilable divisions; a biotope is contaminated for all time, etc.

That is to say, not even AI/ML technologies will simply resolve the contradiction between growth and ecology. More often, they will contribute to it. Beyond this, they also entail other, very specific destructive risks, which we will have to learn to cope with responsibly. If, however, even this most recent and promising facet of digitalisation cannot resolve (or at least drastically mitigate) the antagonism between the growth compulsion of our economic mode and the growth limitations of the (natural and human) substance, then all we are left with once again is a critical consideration of the economic system itself. So, what would have to happen? The dynamics inherent in our economic system, bent as it is on growth and the expansion of markets and consumption, are dramatically at odds with the finite resources and the close-to-exhausted reproductive capacity of nature (and thus our own). Digitalisation-including in its most recent form of Artificial Intelligence and self-learning systems-has a destructive effect when it serves as a mere means to enhance these economic dynamics. This applies when digitalisation is deployed as a productive force, but all the more so when it is used as a distributive force.

As a productive force, digitalisation at least does engender utilisable use values (though not all of them are really useful, and utility often cannot remotely justify the corresponding resource use). Assuming fair mechanisms of distribution, there is a possibility that, with much effort and political will (forming globally), we may be able to use some of these use values sensibly, thereby slightly reducing the mountains of waste and the problem of disposal. Furthermore, digitalisation as a productive force could assist in organising production processes in a way that minimises resource consumption as far as possible and responds to individual demand instantly instead of continuing mass production. 
Yet this would have to be flanked by a completely different use of digitalisation as a distributive force: digitalisation as a distributive force would have to be deployed in the area of advertising and marketing in order to minimise consumption, point out ecological follow-up costs ('externalities') and gradually erode the demand for products without any real use value (who can decide this, through what kind of procedures, remains to be seen-though digitalisation may prove to be a helpful tool for this latter purpose, too). In the area of transport and warehousing, digitalisation as a distributive force would have to minimise ecologically critical transport routes, optimise last-mile delivery in accordance with ecological principles and support more local/regional economic networks through decentralised warehousing.

And, finally, in the area of control and prediction, digitalisation as a distributive force could link up all this with production and consumption locations in a way that allows for organising the fairest possible satisfaction of needs while causing the smallest possible ecological footprint. Beyond this, digitalisation would also have to be used to constantly monitor its own application-both as a productive and a distributive force-as well as permanently minimise its resource use and ecological footprint. This would also mean replacing its own functions with non-digital forms wherever possible, in order to create less resource-intensive alternatives.

Were we to consequently deploy digitalisation in these ways on a global scale, the ecological effects might still be considerable for many people, but could perhaps be mitigated to the extent that nature's reproductive capacity stands a chance-wherever that is even still possible at this point. That said: were we to consequently deploy digitalisation in these ways on a global scale, then that would just about fundamentally counteract our current economic mode-for then there would no longer be any growth (let alone more growth). Were we to consequently deploy digitalisation in these ways on a global scale, a situation of such unequal distribution as today would no longer be possible, seeing as, from an ecological perspective, the accumulation of very much in the hands of very few is always the worst solution, and a more equitable distribution always the better one. This applies to the accumulation of values with an ecological footprint as much as to the risks arising from ecological consequences. Were we to consequently deploy digitalisation in these ways on a global scale, then we might still have a thoroughly digitally based economy, but it would no longer be (more or less digital) capitalism.

In this instance, Karl Marx might have pointed out that such a smooth path of transformation (which would indeed turn our entire way of life upside down) is unrealistic. He would likely interject that those (individual and collective) actors who have thus far benefited from the destructive logic of the 'always more' will not simply surrender their privileges-quite possibly not even in return for the prospect of saving the planet. With regard to the major digital corporations of 
our time, this would also be the ultimate litmus test for the Silicon Valley meme of wanting to make the world a better place. At least for the time being, Silicon Valley actors commonly regarded as unique visionaries are not so much preoccupied with saving the planet, but rather with conquering the moon (Jeff Bezos) and Mars (Elon Musk). Karl Marx would certainly have a valid point when asking why the beneficiaries of the existing system should actively and constructively participate in implementing changes that could herald the end of their astronomical profits.

Nor would Karl Polanyi, we may safely assume, have pinned his hopes on the common sense of those at the top of his market society (bearing in mind, of course, that both Karl Marx and Karl Polanyi never direct their critique at the individual acting in their role as entrepreneur, but are concerned with economic structures and mechanisms). Concerning the first great transformation that Polanyi describes, he has something else in mind: deceleration. And other actors, too: politicians. His own plea to politics is unequivocal: "A belief in spontaneous progress' should not make us blind to the role of government in economic life. This role consists often in altering the rate of change, speeding it up or slowing it down as the case may be [...]" (Polanyi 2001: 39). Today, the free-market oriented, economically liberal state is becoming more and more removed from the principles of the politically liberal (democratic) state. It is therefore no surprise that political actors, consistently opt for acceleration in the context of digital transformation, and-as we have seen-never establish any ecological goals without concomitant growth targets.

Based on an example from the Tudor period, Polanyi shows how the deceleration of enclosures and dispossessions, enforced by the political authorities of the time, at least allowed for those affected to "adjust themselves to changed conditions without fatally damaging their substance, human and economic, physical and moral [and] find new employment [and] new sources of sustenance" (Polanyi 2001: 39). And yet, it is uncertain whether global economic processes, accelerated by the digitalised distributive forces as they are, could even be decelerated by geographically bound social and political processes to begin with. And is it even possible, more generally, to reduce the pace of technological, economic and commercial development to the extent nature would require to be able to adjust to the changes? What other choice do we currently have than to at least work towards deceleration (without losing sight entirely of the option of exiting this economic mode altogether)? And to scrutinise each political decision and deployment of digitalisation in terms of their contribution to deceleration? After all, digitalisation, in its predominant deployment as distributive force and driver of market expansion and consumption in digital capitalism, has so far been geared towards unbridled acceleration.

Bruno Latour's call to Love your Monsters (2011) might in fact open up a third path, although it remains to be seen whether such a postmodernist turn is pos- 
sible without radically restructuring the economy. He urges us to take on sincere concern for the consequences of our actions simply as a normal responsibility. At the same time, he rejects the dominant position among eco-activists (i.e. calls for self-restriction) as an ultimately early-modernist notion, in that it entails the scandalisation of unanticipated consequences: "[...] the return of unexpected consequences appears as a scandal (which it is for the modernist myth of mastery) [...]" (ibid.: 24). His position is that unexpected consequences ought to be dealt with as we have always done (so he asserts), namely by "intervening, acting, wanting, caring"-only more explicitly, more consequently and at an "ever-increasing scale" (ibid.).

By the time this book is published, Bruno Latour's call cited here will be a decade old. A decade in which digitalisation-particularly in its use as a distributive force-has exponentially scaled Latour's monsters. It is in fact questionable whether we even have the time to discuss differing positions among those who have already identified the protection of the natural environment as an existential imperative. The limitless use and exploitation of humans, nature and society will hardly be mitigated or even stopped simply by one group imposing restrictions on themselves and another expanding care activities. We will be increasingly unable to avoid asking about the systemic reasons for the perpetual creation of one monster after another-and why a systematic engagement with unexpected consequences is possible only when it can be turned into a business model. This issue of the monster as such, however, needs to be resolved not only discursively, but in real terms. And there is little time left to do so. Otherwise, Latour's monsters will prevail. 